\title{
A Oralidade Infantil e Desenvolvimento Cognitivo à partir da Prática Docente.
}

(The Orality of Children and Cognitive Development from the Teaching Practice.)

\author{
Gomes Celestino, Patricia \\ Escola Municipal Professora Marisa Filomena do Amaral (Brasil)
}

Páginas 51-67

Fecha recepción: 12-10-2018

Fecha aceptación: 30-11-2018

\section{Resumo.}

Este trabalho tem o objetivo analisar como a prática docente contribui para 0 desenvolvimento da oralidade infantil e suas capacidades cognitivas na Escola Municipal de Educação Infantil, Professora Marisa Filomena do Amaral, localizada na cidade Bragança Paulista, estado de São Paulo no ano de 2015. A metodologia é de caráter qualitativa, as técnicas utilizadas foram entrevista, grupo focal e observação. A população estava formada por professores, pais e alunos. A amostra não é probabilística. No âmbito da discussão são abordadas vertentes sobre a relação entre a fala e a escrita. Acreditando-se num processo de relação entre a fala e a escrita recebeu um tratamento mais adequado que permite aos usuários da língua mais conforto em suas atividades discursivas. Esclarecer a natureza das práticas docentes que envolvam o uso da língua escrita e falada de um modo geral, exemplificando e conceituando a importância da oralidade desde as séries iniciais. A escola é o norte para que a oralidade seja trabalhada em situações comunicativas no trabalho, política e relações interpessoais, fazendo sentido ao aluno naturalmente em sala de aula.

Palavras-chave: aluno; escola; oralidade infantil; prática docente; professor

\section{Abstract.}

This work aims to analyze how the teaching practice contributes to the development of children's orality and their cognitive abilities in the Municipal School of Early Childhood Education, Professora Marisa Filomena do Amaral, located in the city Bragança Paulista, state of São Paulo, in the year 2015. methodology is qualitative, the techniques used were interview, focus group and observation. The population was made up of teachers, parents and students. The sample is not probabilistic. In the scope of the discussion are discussed aspects about the relation between speech and writing. Believing in a process of relationship between speech and writing received a more appropriate treatment that allows language users more comfort in their discursive activities. Clarify the nature of teaching practices that involve the use of written and spoken language in general, exemplifying and conceptualizing the importance of orality since the initial grades. The school is the north so that orality is worked in communicative situations in work, politics and interpersonal relations, making sense of the student naturally in the classroom.

Keywords: student; school; orality; teaching practice; teacher 


\section{1.-Introdução.}

A linguagem oral é uma das particularidades da raça humana, pois é através dela que os seres humanos realizam a comunicação, ocorrendo uma interação entre os indivíduos. Por meio da comunicação podem ser expressas suas ideias, emoções, projetos, troca de conhecimentos e as dúvidas.Mostrando assim a importância da linguagem como uma poderosa ferramenta de socialização e de aprendizagem, na medida em que serve de elemento para troca de conhecimentos, seja por via oral ou por escrito.

Diversos são os fatores que contribuem para os problemas da linguagem de um aluno, tais como: as deficiências intelectuais, físicas ou sensoriais são consideradas elegíveis para a Educação Especial. Referente aos problemas específicos da linguagem, eles podem ser temporários ou permanentes, sendo necessária a realização de exame neurológico, para que fique evidenciado que tais funcionalidades estão em perigo de uma forma permanente.

Por mais que o professor pretenda ser um agente ativo diante dos alunos com dificuldades de aprendizagem, relacionadas com a linguagem oral, ele deve ter 0 apoio de todo um grupo de profissionais que 0 auxilia nesse processo de ensino, pois é humanamente impossível que ele realize todos os processos para que a criança atenue ou consiga abolir suas dificuldades.

Para a construção da pesquisa, necessitou-se de várias leituras referente ao tema, como em livros, artigos, revistas e outros. Foram essenciais leituras de Vygostky (1996), Piaget (1996), Rego (2003) que deram suporte para a tessitura do referencial teórico.

Os professores reconhecem os problemas da linguagem oral quando se deparam com as dificuldades de aprendizagens e muitos não estão preparados para trabalhar com esses alunos, isso ocorre devido as situações vivenciadas em sala de aula e no convívio das crianças nos diferentes espaços de aprendizagem revelando inúmeros problemas como: falta de formação continuada dos professores, timidez das crianças, falta de atividades que estimulem a oralidade e ajude no desenvolvimento cognitivo dos mesmos.

O problema da pesquisa é: Como a prática docente contribui para o desenvolvimento da oralidade infantil e suas capacidades cognitivas, na Escola Municipal de Educação Infantil Professora Marisa Filomena do Amaral, estabelecida na cidade de Bragança Paulista, estado de São Paulo no ano de 2015?

O Objetivo geral é: Analisar a contribuição da prática docente para 0 desenvolvimento da oralidade infantil e suas capacidades cognitivas, na Escola Municipal de Educação Infantil Professora Marisa Filomena do Amaral, da cidade de Bragança Paulista, no estado de São Paulo no ano de 2015.

Os Objetivos específicos são: a) Identificar os benefícios que a linguagem oral proporciona às crianças da Educação Infantil; b) Determinar como à oralidade docente contribui no desenvolvimento da oralidade dos alunos e seu desenvolvimento cognitivo; c) Reconhecer a importância da formação continuada de professores para o desenvolvimento da oralidade infantil; d) Estabelecer estratégias 
que o professor deve utilizar para contribuir com o desenvolvimento da oralidade infantil;

A pesquisa se justifica por que atualmente, com 0 avanço da tecnologia, a oralidade entre as pessoas e a empatia diminuiu bastante, pois o convívio familiar e social perdeu espaço para os novos jogos e softwares encontrando-se disperso e confinado. Por isso, a oralidade desde os primeiros anos de vida e em idade escolar, tornou-se grande relevância para que haja sempre uma comunicação, sem perder a interação entre as pessoas.

Um aspecto relevante refere-se ao estudo social, sendo que seus resultados poderão contribuir para a melhoria da aprendizagem, relações professor-aluno, auto estima dos discentes, desenvolvimento oral e cognitivo. Dessa forma, a presente pesquisa servirá para nortear outros estudiosos a realizarem trabalhos dessa natureza, já que essa temática não se esgota aqui e sugerem perspectivas que ajudem os professores a desenvolverem alternativas no campo da oralidade infantil. Assim, 0 impacto desse estudo e sua relevância será de grande valia para a comunidade escolar.

\section{2.-Aportes teóricos sobre a linguagem oral na infância.}

A linguagem das crianças intriga linguistas e estudiosos do assunto. Sendo assim crianças do século XII, por exemplo, apesar de crianças como as de hoje não brincavam com os mesmos brinquedos, nem sentiam, nem pensavam, nem se vestiam como as crianças de hoje. $\mathrm{E}$, certamente as crianças deste século terão características muito diferentes das de hoje (Elane et.al, 2007; p. 65). É interessante que assim surge um questionamento: se as crianças de antigamente eram diferentes das de hoje certamente as de amanhã também serão. Por isso é interessante estudar a infância e seu processo no decorrer dos tempos.

Nesta perspectiva, Chaer e Guimarães (2012) ponderam que a linguagem oral é um dos aspectos fundamentais de nossa vida, pois é por meio dela que nos socializamos, construímos conhecimentos, organizamos nossos pensamentos e experiências, ingressamos no mundo. Assim, ela amplia nossas possibilidades de inserção e de participação nas diversas práticas sociais.

De acordo com Elane et.al (2007) a aquisição da linguagem tenta explicar entre outras coisas o fato de as crianças, por volta dos 3 anos, serem capazes de fazer 0 uso produtivo de suas línguas. Desde pequenos já existe a comunicação, mas esta não é feita por meio oral. A linguagem é um sistema de símbolos culturais internalizados, e é utilizada com o fim último de comunicação social. Assim como no caso da inteligência e do pensamento, o seu desenvolvimento passa também por períodos até que a criança chegue a utilização de frases e múltiplas palavras.

Ao nascer, a criança não entende o que lhe é dito. Somente aos poucos começa a atribuir um sentido ao que escuta. Do mesmo modo acontece com a produção da linguagem falada. $O$ entendimento e a produção da linguagem falada evoluem.

Existem diferentes tipos de linguagem: a corporal, a falada, a escrita e a gráfica. Para se comunicar a criança utiliza tanto a linguagem corporal (mímica, gestos, entre outros.) como a linguagem falada. 
Assim, segundo Elane et.al (2007) o desenvolvimento da linguagem se divide em dois estádios:pré-linguístico, quando o bebê usa de modo comunicativo os sons, sem palavras ou gramática; e o linguístico, quando usa palavras. No estádio prelinguístico a criança, de princípio, usa o choro para se comunicar, podendo ser rica em expressão emocional. Logo ao nascer este choro ainda é indiferenciado, porque nem a mãe sabe o que ele significa, mas aos poucos começa a ficar cheio de significados e é possível, pelo menos para a mãe, saber se o bebê está chorando de fome, de cólica, por estar se sentindo desconfortável, por querer colo etc. è importante ressaltar que é a relação do bebê com sua mãe, ou com a pessoa que cuida dele, que lhe dá elementos para compreender seu choro.

Para Elane et.al (2007) ressalta que além do choro, a criança começa a produzir 0 arrulho, que é a emissão de um som gutural, que sai da garganta, que se assemelha ao arrulho dos pombos. O balbucio ocorre de repente, por volta dos 6-10 meses, e caracteriza-se pela produção e repetição de sons de consoantes e vogais como "ma-ma-ma-ma", que muitas vezes é confundido com a primeira palavra do bebê. No desenvolvimento da linguagem, os bebês começam imitando casualmente os sons que ouvem, através da ecolalia. Por exemplo: os bebês repetem repetidas vezes os sons como o "da - da-da", ou "ma-ma-ma-ma". Por isso as crianças que tem problema de audição, não evoluem para além do balbucio, já que não são capazes de escutar.

A fala linguística se inicia geralmente no final do segundo ano, quando a criança pronuncia a mesma combinação de sons para se referir a uma pessoa, um objeto, um animal ou um acontecimento. Por exemplo, se a criança disser apo quando vir a água na mamadeira, no copo, na torneira, no banheiro etc., podemos afirmar que ela já está falando por meio de palavras. Espera-se que aos 18 meses a criança já tenha um vocabulário de aproximadamente 50 palavras, no entanto ainda apresenta características da fala pré-linguística e não revela frustração se não for compreendida (Elane et.al, 2007; p. 76).

$\mathrm{Na}$ fase inicial da fala linguística a criança costuma dizer uma única palavra, atribuindo a ela, no entanto o valor de frase. Por exemplo, diz ua, apontando para porta de casa, expressando um pensamento completo; eu quero ir pra rua. Essas palavras com valor de frases são chamadas holofrases.

Conforme Elane et.al (2007) a partir daqui acontece uma "explosão de nomes", e 0 vocabulário cresce muito. Aos 2 anos espera-se que as crianças sejam capazes de utilizar um vocabulário de mais de cem palavras. Entre os 2 e 3 anos as crianças começam a adquirir os primeiros fundamentos de sintaxe, começando assim a se preocupar com as regras gramaticais. Usam, para tanto, o que chamamos de superregularização, que é uma aplicação das regras gramaticais a todos os casos, sem considerar as exceções. É por isso que a criança quer comprar "pães", trazê-los nas "mães". Aos 6 anos a criança fala utilizando frases longas, tentando utilizar corretamente as normas gramaticais

A linguagem é uma ferramenta que possibilita o pensamento, e consequentemente permite a comunicação abrangente dele. E é por meio da linguagem, seja internalizada ou não, que a criança consegue organizar seus pensamentos, sendo possível seguir uma cronologia e obtendo uma organização de pensamento claro e encadeado. Como escreve Costa (2011; p. 39) 
A linguagem oral é também uma forma de comunicar, mas é uma forma muito especial de comunicar, é uma faculdade de expressão especificamente humana, que não se encontra em outras espécies. Com o seu caráter distintamente humano, a linguagem é porventura o mais poderoso instrumento de comunicação conhecido.

Como bem ressalta a autora, a oralidade não é só mais uma maneira de comunicação, mas é uma particularidade humana, por isso torna-se tão importante e um poderoso instrumento que é usando desde os primeiros dias de vida.

Ela ainda pode ser analisada como um dos eixos norteadores da ação pedagógica com crianças, pois através da linguagem as crianças se comunica e mantém uma relação com o mundo ao seu redor, influenciando no seu desenvolvimento. Sabemos que o ser humano é constituído de múltiplas linguagens, e nesse trabalho, nesse primeiro momento, teremos como análise a importância da linguagem oral, no processo de aprendizagem das crianças.

Ao nascer as crianças, já possuem um saber próprio, que assim os auxiliam para atuarem no meio em que vive. Através da prática da interação entre seus pares, a inteligência do menor vai formando-se e dando significados àquilo que está ao seu redor. Como esclarece Oliveira et all (2011; p. 47):

A interação da criança desde ao nascer transforma interiormente sua forma de pensar atuando em seu meio, modificando sua forma de pensar. Desde bebês já articulam sons para se comunicar com o meio social, sendo colocados neste mundo de diálogos, os adultos interpretam essa linguagem, dando significado a essa linguagem.

Nesse sentido a comunicação oral, torna-se uma das mais importante formas de expressão, seja a oralidade formal ou informal, pois oportuniza às crianças uma expressividade da sua língua. Desde muito cedo, até mesmo antes de entrarem nas creches ou nas escolas, as crianças demonstram e possuem interesse em tentar compreender as falas e os atos dos adultos nas condutas comunicativas. Podemos exemplificar quando um bebê, já tem o poder de distinguir, por meio da entonação e das expressões, na conversação entre os adultos ou com ele, no momento de leituras quando contam ou quando leem uma história.

Segundo Oliveira et all (2011) o pensamento das crianças vão tornando-se cada vez mais complexos, devido a interação com seu meio, abrindo o leque de linguagem e coordenação de suas ações. Nessa perspectiva cria-se significados, relacionando 0 concreto e as experiências.

Partindo do pressuposto, de que a oralidade é uma modalidade de comunicação, por meio da fala ela tem 0 poder de transformar o pensamento dos indivíduos em palavras, dando sentido a elas, as ideias, aos sentimentos e aos desejos. Mesmo sendo uma especificidade dos seres humanos possuir a genética de poder falar, ele só irá ocorrer e se desenvolver se existir interações entre os falantes.

Assim a oralidade deve está presente nas interações pedagógicas, que devem ser bem planejadas, pois assim terá uma aprendizagem mais favorável, e quando tem alguma dificuldade a intervenção do adulto é necessária, mas tal intervenção deve ser cautelosa, pois quando 0 adulto utiliza uma linguagem infantilizada, pode representar para criança, um sinal de menosprezo, colocando a prova a capacidade da criança em seu desenvolvimento, pois os adultos são espelhos para crianças. 
$\mathrm{Na}$ realização de seus estudos, Vygotsky (2003) desenvolve etapas que 0 pensamento e a oralidade, são de grande importância para 0 indivíduo principalmente no desenvolver da intelectualidade. As etapas são as seguintes:

Etapa pré-oralidade do pensamento: Nessa etapa há a predominância de uma inteligência prática, ou seja não tem a presença da oralidade. Temos como exemplo, quando um bebê que quer pegar um objeto em cima da mesa, simplesmente ele puxará a toalha para assim trazê-lo para perto. A resolução do problema é na ação prática, sem planejar, portanto, evolui sem que houvesse uma linguagem falada.

Etapa da oralidade intelectual e o pensamento verbal: Nesta etapa as crianças já conseguem pensar usando palavras, representando o mundo por conceitos, verbalizando os seus pensamentos. Já conseguem nomear animais, pessoas, objetos entre outros, o adulto tem um papel fundamental de interação, que pode ser realizada por meio de jogos, brincadeiras e diálogos. A criança aprende a indagar, interpretar e organizar por meio de palavras a sua fala.

Assim, o estudioso divide em fases o processo que as crianças passam para começar utilizar uma linguagem mais organizada e estruturada, pois é ao longo dos anos que ela vai formalizando e estruturando seus pensamentos e atitudes.

Nesse sentido, o pensamento e a linguagem interligam-se, o pensamento é a maneira verbal e a fala já é racional. Vygotsky (2003) afirma que há três níveis de aprendizagem e desenvolvimento da criança: o da zona de desenvolvimento potencial, zona de desenvolvimento real e zona de desenvolvimento proximal.

A zona de desenvolvimento potencial é aquela, em que não se espera mais da criança do que ela pode oferecer, na zona de desenvolvimento real é a fase em que o menor consegue realizar as coisas sozinhas e na zona de desenvolvimento proximal a criança só realiza alguma coisa com a ajuda do outro.

Partindo desses pensamentos, observa-se que a aquisição da linguagem oral é um processo de apropriação que ocorre com a presença do outro, nessa interação as crianças iniciam sua fala, ampliando seu vocabulário e consequentemente the ajudará nos problemas que irá aparecer ao longo do tempo.

A linguagem é um instrumento que ajuda o indivíduo na resolução de problemas. A linguagem específica do ser humano, em todo o seu desenvolvimento auxilia, além de solucionar problemas, também planeja uma solução para um problema antes deste ocorrer e ainda controlar seu próprio comportamento. A base são as funções cognitivas e comunicativas da linguagem que fazem com que a criança interaja com o meio social em que vive, assim signos e palavras tornam-se um meio de contato social com outras pessoas distinguindo-as dos animais.(Vygotsky, 2003; p.38).

Assim, o uso da linguagem traz grandes benefícios para a sociedade, e por isso desde a infância ela deve ser bem trabalhada, pois quando isso não ocorre nos primeiros estágios de vida, pode comprometer o desenvolvimento da criança.

Para Piaget (1996), que nos seus estudos desenvolve acerca do método clínico. Nele a criança está no centro das investigações, em suas análises concluiu que a inteligência é construída através da relação estabelecida com o objeto, ultrapassando as concepções clássicas.

Para 0 autor, a criança aprende sempre do individual para o coletivo. Cabe ressaltar a importância crucial da relação do sujeito com o ambiente, onde a aquisição e 0 desenvolvimento da linguagem derivam de processos do desenvolvimento do 
raciocínio da criança. Sendo que através da interação do indivíduo com o meio físico, ele consegue construir estruturas cognitivas de sua inteligência, e estes esquemas mentais facilitam a aprendizagem sobre a realidade.

O desenvolvimento cognitivo da linguagem, de acordo com Piaget (1996), ocorre gradualmente partindo do nível mais básico de processos sensoriais e motores até os níveis mais complexos, denominados de funções mentais superiores, de que 0 hipotético dedutivo pensado - é a parte superior. Entre um e outro é o funcionamento simbólico e pensamento conceptual.

Referente ao construtivismo-cognitivista que é a linguagem vinculada à cognição. Piaget em sua investigação denominou epistemologia genética para 0 desenvolvimento natural da criança, no qual seu estudo visualizou as concepções infantis de tempo, causalidade física, espaço, movimento e velocidade. Segundo ele, através da ação do ser humano ao meio é que as habilidades intelectuais são formadas, sendo o pivô para que o desenvolvimento do conhecimento aconteça.

Segundo Piaget (1990), o conhecimento se fundamentaliza por meio da interação entre 0 organismo e o meio no qual está inserido. Em vista disso, a oralidade entre as pessoas deve ser iniciada desde muito cedo e nas relações entre professor e aluno e da família com o indivíduo não é diferente, pois essas relações contribuem diretamente no desenvolvimento da criança.

Considerando a importância da interação entre família, alunos e professores, pois quando não existe essa comunicação entre esses seres, há um egocentrismo, que é o caráter pré-lógico do raciocínio infantil e passa por alguns estágios e quando começa o período da maturação do pensamento, este estágio de egocentrismo vai diminuindo gradualmente, criando assim a noção de responsabilidade individual que é responsável pela autonomia dela. Segundo a teoria de Piaget, existem quatro estágios do desenvolvimento cognitivo, são os seguintes:

O primeiro estágio chamado de sensório-motor está presente até os dois anos, nele as crianças conseguem administrar seus reflexos básicos, que geram satisfação, sendo um período que antecede à linguagem, em que 0 indivíduo, no caso 0 bebê consegue desenvolver a percepção dela mesma e dos objetos que a rodeiam, assim é o período em que os bebês fazem o reconhecimento daquilo que lhe cerca.

O segundo estágio é o pré-operacional vai dos dois aos sete anos, nesse momento estrutura-se a capacidade de dominar a linguagem e a representação do mundo por símbolos. Nesta fase a criança não consegue se colocar no lugar de outra pessoa, ou seja, moralmente, e nem saiu do egocentrismo, ressalta Jaime Zorzi (1993):

"(...) está ligado à formação da função simbólica que diz respeito à capacidade de representar. Tal função envolve, além da linguagem e da brincadeira simbólica as imagens mentais, a imitação diferida e a resolução de problemas por combinação mental de ações. O simbolismo, enfim, se estende a todas as condutas que revelam a capacidade de evocar coisas ou situações ausentes, que vão além daquilo que pode ser percebido" (p.15).

O terceiro estágio é 0 das operações concretas, essa fase vai dos sete aos onze ou doze anos, ocorre a capacidade de reversibilidade das ações. Nos processos mentais surge a lógica e a discriminação dos objetos pela similaridade e diferenças, no qual as crianças já tem noções acerca de conceitos de número e tempo. 
O quarto estágio é o das operações formais, aproximadamente pelos doze anos de idade, nessa fase tem-se 0 iniciar da vida adulta. Nesse estágio o adolescente já consegue dominar 0 pensamento lógico e dedutivo, possibilitando algumas habilidades no que refere-se a experimentação mental. Conseguindo abstrair e raciocinar suas hipóteses. Segundo Piaget, ao atingir esta fase 0 indivíduo consegue equilíbrio, alcançando o padrão intelectual para toda sua vida.

Portanto, os estágio abordados por Piaget, contribuem para entender o processo de evolução desde criança, até chegar a fase adulta, contribuindo para o processo de aprendizagem do indivíduo.

A teoria piagetiana quando relata sobre aquisição da linguagem integra-se com a capacidade cognitiva, ou seja, há uma exaltação da inteligência da criança, em relação a ação biológica, ou seja, os aspectos cognitivos se sobressaem em relação os aspectos biológicos, pois esses conseguem adaptar-se ao meio físico.

É nos primeiros contatos com o mundo, que as crianças começam a desenvolver a comunicação, e esse primeiro momento é semelhante a todos nos primeiros meses de idade, é neste momento em que a linguagem está começando a aflorar na criança, na qual podemos verificar que o ser humano é dotado de uma capacidade verdadeiramente única no reino animal. Como esclarece Chomsky (1968, p. 45) um teórico da modernidade linguista.

A comunicação é um método real, em que há troca de conhecimento e informações, sendo estas reconhecida mundialmente, mesmo com a existência de idiomas diferentes, isso não impede para que a comunicação venha acontecer.

A linguagem moral é, sem sombra de dúvida, a particularidade e umas das únicas características que pertence ao grupo dotado de raciocínio e emoções, nesse sentido os seres humanos são os únicos animais que tem função a prática da comunicação. Como escreve Costa (2011; p.36):

A linguagem é uma forma de ação sobre o que nos rodeia, uma expressão do desenvolvimento, uma confirmação da evolução humana ao longo da sua existência, uma ferramenta de tal maneira importante, capaz de influenciar tomadas de decisão importantes no rumo da humanidade, através das técnicas de marketing tão importantes hoje em dia na nossa sociedade.

\section{1-As contribuições da linguagem oral na Educação Infantil.}

$\mathrm{Na}$ Antiguidade, a criança desde muito cedo devia ser punida e corrigida. Como não haviam estudos específicos na área da educação infantil, e tal modalidade de ensino poderia ser obtida no meio familiar por meio da interação entre as crianças e os adultos, pois assim era transmitido a cultura de uma sociedade e o processo de aprendizado se construía somente na contemporaneidade que as crianças teriam um espaço especializado, em que pode interagir com outras crianças.

Durante o medievo, na Europa, os menores eram tratados como seres humanos deficitário, um adulto pequeno, em miniatura, devendo crescer para ajudar no trabalho com a família. Os excluídos eram rejeitados na roda dos expostos. A Igreja, a instituição mais rica durante o período, recolhiam estas crianças e ao crescer ensinavam-Ihes determinado ofício. 
Segundo Oliveira (2011) àquelas que pertenciam as famílias mais abastadas, geralmente eram vistas como objeto divino e misterioso, cuja transformação em adulto também se fazia pela direta imersão no ambiente doméstico. Nesses casos, haviam trocas de carinho entre os adultos e as crianças, mas sempre considerando a existencia de uma identidade pessoal.

Nos séculos XV e XVI, criaram novos modelos pedagógicos, direcionando como as crianças deveriam ser educadas e, como deveriam ser estimuladas, respeitar a natureza da criança e ainda haver uma associação do jogo com a aprendizagem.

No processo de transição do feudalismo para o capitalismo, as rupturas não aconteceram somente nas esferas econômicas, sociais e culturais, pois muitas práticas foram transformadas, como ocorreu com a revolução industrial e nas guerras, as mulheres foram obrigadas a trabalhar fora, surgindo então instituições para cuidar das crianças, para assim diminuir a mortalidade infantil e atender aos filhos destas mulheres que trabalhavam nas fábricas. Como relata Oliveeira et all (2011; p.79).

O enorme impacto causado pela revolução industrial fez com que toda a classe operária se submetesse ao regime da fábrica e das máquinas. Desse modo, essa revolução possibilitou a entrada em massa da mulher no mercado de trabalho, alterando a forma da família cuidar e educar seus filhos.

Assim com a saída das mulheres dos lares para o mercado de trabalho, não tinham com quem deixar seus filhos, então emerge na sociedade as mães mecenárias, que eram aquelas mães que vendiam seus trabalhos, como olhares e abrigarem as crianças enquanto as mulheres estão nas fábricas trabalhando.

\section{3.-Metodologia.}

Essa pesquisa buscou analisar o desenvolvimento da linguagem oral como uma forma prática e imprescindível do ser humano para sua comunicação, para construção do trabalho, além dos referenciais que abordam sobre 0 desenvolvimento da linguagem oral, principalmente dos alunos da educação infantil, utilizou-se de entrevistas e conversas com alunos, professores e pais, pois são elementos essenciais no processo de aprendizagem e desenvolvimento das crianças.

O lugar da pesquisa: foi realizada na Escola Municipal de Educação Infantil Professora Marisa Filomena do Amaral, com professores, pais e alunos localizada na cidade Bragança Paulista, estado de São Paulo no ano de 2015.

Utilizou-se a pesquisa descritiva. Os estudos descritivos buscam especificar as propriedades, as características e os perfis importantes de determinadas pessoas, grupos ou comunidades. Fazem uma avaliação ou recolhimento de dados. No estudo descritivo é selecionado uma série de questões e se mede, coleta-se informações sobre cada uma delas, para assim descobrir o que se está investigando. (Marconi e Lakatos, 2009; p. 56).

Utilizou-se um enfoque qualitativo. As pesquisas qualitativas utilizam análises textuais, podendo partir de textos já existentes, ou desenvolver o material de análise por meio de entrevistas e observações, tal pesquisa pretende aprofundar a compreensão dos fenômenos que investigam a partir de uma análise precisa, rigorosa e criteriosa para esse tipo de informação, isto é, não pretende testar 
hipóteses para comprová-las ou refutá-las ao final da pesquisa, mas pretende buscar a compreensão. (Marconi e Lakatos, 2009; p. 67).

Se utiliza para descobrir e refinar perguntas da investigação. Não necessariamente se produzem hipóteses. Com frequência se baseia em métodos de coleta de dados sem medição numérica, como as descritivas e as de observação. Seu propósito consiste em reconstruir a realidade, tal e como observam os autores de um sistema social, previamente definido.

A População: A escola é de rede municipal e a frequência dos alunos é assistida pela escola e também por outro órgão municipal o Conselho Tutelar. O estudo contará com uma população de 200 alunos e 10 professores. A Amostra: A pesquisa terá a amostra composta por 17 alunos com idade de 4 anos (observação), 7 professores (entrevista) e 8 pais (grupo focal). Amostra não probabilística é obtida à partir de alguns critérios, e nem todos os elementos da população tem a mesma chance de ser selecionados evitando que os resultados sejam generalizados. (Oliveira, 2007; p. 83).

Técnicas e instrumentos de coleta de dados: Instrumentos de coleta de dados:serão utilizados os seguintes instrumentos. Observação através de indicadores, grupo focal por meiode questionários e nas entrevistas utilizou-se perguntas guias referentes ao objeto de estudo. Observação: Termo do latim observativo a observação é a ação e 0 efeito de observar (examinar com atenção, olhar com pormenor, constatar). Tratase de uma atividade realizada pelos seres vivos para detectar e assimilar informação. A observação se realizou em uma turma de crianças de 4 anos durante nove meses, sendo uma observação não participante. Entrevista: Segundo Oliveira (2007) é uma técnica que busca obter informações no qual os indivíduos sabem, esperam, sentem ou desejam e sabem expressar-se sobre seus pensamentos e razões. Serão realizadas entrevistas com 7 professores da escola pesquisada com 0 intuito de descobrir como esses professores trabalham a oralidade infantil, como é realizado 0 planejamento de aulas e se eles associam a oralidade ao desenvolvimento cognitivo da criança.

\section{4.-Discussão dos Resultados.}

4.1.-Resultado da análise da entrevista com os professores.

Tabela 01: Qual sua formação acadêmica?

\begin{tabular}{c|c}
\hline \multicolumn{2}{c}{ Qual sua formação acadêmica? } \\
\hline Professores & Formação Acadêmica \\
\hline Todos Professores & Têm curso Superior Completo \\
\hline
\end{tabular}

Fonte: dados da pesquisa.

Quando questionados sobre sua formação acadêmica, todos os entrevistados possuem curso superior na área da Educação.

Tabela 02: Sua atualização com relação ao trabalho sobre oralidade em sala de aula.

Sua atualização com relação ao trabalho sobre oralidade em sala de aula. 


\begin{tabular}{l|l}
\hline Professores & \multicolumn{1}{c}{ Respostas } \\
\hline Professor 1 & Se atualiza através de cursos oferecidos pela escola. \\
\hline $\begin{array}{l}\text { Professor } 2 \\
\text { e } 5\end{array}$ & Se atualiza por cursos fora da rede municipal de ensino. \\
\hline Professor 3 & Se atualiza através das reuniões de HTPCs. \\
\hline Professor 4 & Se atualiza através de cursos fora da rede municipal de ensino. \\
\hline Professor 6 & Se atualiza através de leituras realizadas nas reuniões na escola. \\
\hline Professor 7 & Se atualiza através de cursos realizados pela escola. \\
\hline
\end{tabular}

Fonte: dados da pesquisa.

Pode-se observar que todos os professores procuram se atualizar sobre a oralidade infantil, mesmo não ocorrendo cursos oferecidos pela rede municipal de ensino, ou seja, estão sempre procurando estar informados e buscando se capacitar nas questões relacionadas ao tema.

Tabela 03:Qual intensidade você costuma desenvolver a oralidade das crianças em sala de aula?

\begin{tabular}{l|l}
\multicolumn{2}{c}{ Qual intensidade você costuma desenvolver a oralidade das crianças em sala de } \\
aula?
\end{tabular}

Fonte: dados da pesquisa.

Observa-se que em seis casos o professor desenvolve a questão da oralidade diariamente, com frequência é explorada com seus alunos. Já com um professor, que chamamos de P2 esta atividade ainda é limitada em três dias por semana, onde através de estudos da pesquisadora tal atividade deve ser trabalhada todos os dias para estimular seu aluno.

Tabela 04: Em relação a sua experiência profissional e prática docente como contribui positivamente no desenvolvimento da oralidade de seu aluno?

\begin{tabular}{c|l}
\hline \multicolumn{2}{c}{$\begin{array}{c}\text { Em relação a sua experiência profissional e prática docente como contribui } \\
\text { positivamente no desenvolvimento da oralidade de seu aluno? }\end{array}$} \\
\hline Professores & \multicolumn{1}{c}{ Respostas } \\
\hline P1 & $\begin{array}{l}\text { Realiza atividades diárias interferindo nos momentos que os } \\
\text { alunos estão se expressando em temas relativos à oralidade, } \\
\text { questionando-os para que consigam estabelecer mecanismos de } \\
\text { ajustes de conversas para que ajuste seu pensamento } \\
\text { construindo frases mais completas. }\end{array}$ \\
\hline P2 & $\begin{array}{l}\text { acredita que sua prática docente ajuda a criar momentos no } \\
\text { ensino da oralidade infantil. }\end{array}$ \\
\hline
\end{tabular}




\begin{tabular}{l|l}
\hline P3 & $\begin{array}{l}\text { Relata que em seu trabalho diário ocorrem momentos em que a } \\
\text { oralidade favorece o desenvolvimento cognitivo. }\end{array}$ \\
\hline P4 & $\begin{array}{l}\text { Em sua experiência profissional e com sua prática consegue } \\
\text { articular as atividades em sala de aula, proporcionando } \\
\text { momentos de prazer à seus alunos, ricos de estímulos para o } \\
\text { desenvolvimento da oralidade. }\end{array}$ \\
\hline P5 & $\begin{array}{l}\text { Menciona que faz parte de sua rotina o trabalho com a oralidade, } \\
\text { onde ele avalia constantemente seus alunos no que diz respeito } \\
\text { à sua oralidade. }\end{array}$ \\
\hline P6 & $\begin{array}{l}\text { Diz que sua prática facilita no trabalho que faz com seus alunos. } \\
\text { P7 } \\
\text { buscar meios de estimular seus alunos para que se desenvolvam } \\
\text { oralmente. }\end{array}$ \\
\hline
\end{tabular}

Fonte: dados da pesquisa.

Conclui-se que por meio da experiência profissional e sua prática em todas as falas dos professores auxilia no seu trabalho e com a oralidade os alunos conseguem se desenvolver contribuindo nas suas habilidades.

4.2.-Resultado da análise do grupo focal aplicado com os pais.

Tabela 05: Como favorece a seus filhos a formação continuada dos professores? Como favorece a seus filhos a formação continuada dos professores?

\begin{tabular}{l|l}
\hline Professores & \multicolumn{1}{c}{ Respostas } \\
\hline P1 & $\begin{array}{l}\text { Responde que com mais cursos realizados pelos professores o } \\
\text { ensino melhora. }\end{array}$ \\
\hline P2 & $\begin{array}{l}\text { Responde que como 0 professor está tendo uma formação } \\
\text { continuada meu filho terá mais aprendizagem. }\end{array}$ \\
\hline P3 & $\begin{array}{l}\text { Responde que com esta formação dos professores meu filho } \\
\text { melhorou mais sua linguagem em casa. }\end{array}$ \\
\hline P4 & $\begin{array}{l}\text { Relata que com cursos de formação o professor pode aplicar o que } \\
\text { aprendeu em sala de aula, assim meu filho aprende mais. }\end{array}$ \\
\hline P5 & $\begin{array}{l}\text { Responde que se o professor faz curso, quem se beneficia são os } \\
\text { alunos na escola. }\end{array}$ \\
\hline P6 & $\begin{array}{l}\text { Assevera que se estudando mais a qualidade melhora, assim o } \\
\text { aprendizado na escola se intensifica. }\end{array}$ \\
\hline
\end{tabular}

Fonte: dados da pesquisa.

Tabela 06: Como o trabalho realizado pelos professores melhora a fala das crianças?

\begin{tabular}{l|l}
\hline Professores & \multicolumn{1}{c}{ Respostas } \\
\hline P1 & $\begin{array}{l}\text { Responde que com um profissional especializado as crianças } \\
\text { conseguem aprender mais neste mundo letrado. }\end{array}$ \\
\hline P2 & $\begin{array}{l}\text { Responde que com atividades que o professor aplica em sala de } \\
\text { aula, socializando com os alunos, aprender a conversar e contar }\end{array}$ \\
\hline
\end{tabular}




\begin{tabular}{l|l}
\hline & $\begin{array}{l}\text { fatos de seu cotidiano para o professor, aprendendo a falar cada } \\
\text { vez melhor. }\end{array}$ \\
\hline P3 & $\begin{array}{l}\text { Fala que a criança adquire junto com o professor a falar com um } \\
\text { vocabulário melhor. }\end{array}$ \\
\hline P4 & $\begin{array}{l}\text { Menciona que com o trabalho do professor desde cedo com os } \\
\text { alunos, estimulando sua fala, a criança acostuma a falar diante de } \\
\text { qualquer situação sem tem receio de errar. }\end{array}$ \\
\hline P5 & $\begin{array}{l}\text { Relata que o trabalho do professor se intensifica com o que a } \\
\text { família vem se desempenhando em casa, assim estimulando na } \\
\text { escola a criança melhora sua linguagem. }\end{array}$ \\
\hline P6 & $\begin{array}{l}\text { Responde que os professores trabalhando com dedicação com } \\
\text { seus alunos, havendo uma afetividade entre eles, a criança } \\
\text { aprende tudo o que o professor quiser, melhorando seu } \\
\text { desempenho. }\end{array}$ \\
\hline Pduz que o trabalho do professor se intensifica com atividades \\
voltadas a esta capacidade da fala, melhorando cada vez o \\
vocabulário dos alunos.
\end{tabular}

Fonte: dados da pesquisa.

Neste questionamento os pais acreditam que com 0 trabalho desenvolvido pelos professores em sala de aula com seus filhos auxiliou na fala das crianças em sala de aula e em casa, portanto é necessário que o professor trabalhe diariamente com os alunos motivando a fala de cada um deles em todas as atividades dirigidas ou não pelo professor, auxiliando a oralidade de cada um deles, apresentando atividades que possibilite a expressão linguística.

Tabela 07: Você percebeu que ampliou o repertório de histórias contadas e recontadas pelo seu filho em casa depois da prática em aula?

\begin{tabular}{l|l}
\multicolumn{2}{c}{ Você percebeu que ampliou o repertório de histórias contadas e recontadas pelo } \\
seu filho em casa depois da prática em aula?
\end{tabular}

Fonte: dados da pesquisa.

Diante das respostas dos pais conclui-se que com a ida de seu filho à escola melhorou muito o repertório de histórias contadas e recontadas em casa e na escola. 
Portanto, há necessidade de estimular os alunos a momentos de leituras e recontos de histórias para que consigam relatar o que entenderam da história contada, empréstimos de livros para serem lidos em casa por eles e pelos pais, criando 0 hábito de leitura. Assim um projeto de leitura praticado na escola por todas as salas de aula, conduz a uma comunidade leitora desde cedo.

Tabela 08: O que você acredita ser importante para o desenvolvimento cognitivo da oralidade de seu filho?

\begin{tabular}{|c|c|}
\hline \multicolumn{2}{|c|}{$\begin{array}{l}\text { O que você acredita ser importante para o desenvolvimento cognitivo da oralidade } \\
\text { de seu filho? }\end{array}$} \\
\hline Professores & Respostas \\
\hline P1 & $\begin{array}{l}\text { Responde que se faz necessário atividades na escola para que } \\
\text { possa desenvolver cognitivamente, melhorando a oralidade. }\end{array}$ \\
\hline P2 & $\begin{array}{l}\text { Responde que com atividades lúdicas ocorre } 0 \text { desenvolvimento } \\
\text { cognitivo. }\end{array}$ \\
\hline P3 & $\begin{array}{l}\text { Responde que com o trabalho do professor em classe auxilia no } \\
\text { desenvolvimento cognitivo das crianças e a oralidade. }\end{array}$ \\
\hline P4 & Responde que é importante trabalhar a fala dos alunos. \\
\hline P5 & $\begin{array}{l}\text { Responde que atividades direcionadas a oralidade auxilia } 0 \\
\text { desenvolvimento cognitivo. }\end{array}$ \\
\hline P6 & Responde que trabalhar atividades que estimulem a oralidade. \\
\hline P7 & $\begin{array}{l}\text { Responde que para o desenvolvimento cognitivo da oralidade na } \\
\text { escola deve se trabalhar momentos que o aluno consiga ter acesso } \\
\text { a materiais que desenvolvam a oralidade. }\end{array}$ \\
\hline
\end{tabular}

Fonte: dados da pesquisa.

Quando questionado sobre que atividades contribuem para o desenvolvimento cognitivo da oralidade, os pais responderam que são aquelas atividades que visa e estimulam a oralidade das crianças, atividades nos quais a oralidade esteja em evidência.

\section{5.-Conclusão.}

A oralidade mostra-se como imprescindível no processo de ensino aprendizagem, e ela deve ser estimulada desde 0 iniciar de sua vida social, e quando adentrar no meio escolar e na educação infantil. $\mathrm{Na}$ sala de aula cabe ao professor fazer 0 reconhecimento das dificuldades apresentadas pelo os alunos e buscar meios pra amenizar ou solucionar esses obstáculos

Com as pesquisas bibliográficas, observação em sala de aula com crianças de 4 anos e reflexão dos dados para analisar e responder as questões relativas à pesquisa, a saber: A importância da formação continuada de professores para 0 desenvolvimento da oralidade infantil; A prática docente contribui no ensino da oralidade dos alunos e seu desenvolvimento cognitivo; Estratégias e recursos 0 professor utiliza para poder contribuir com o desenvolvimento da oralidade infantil; Benefícios do desenvolvimento da linguagem oral proporciona às crianças da 
Educação Infantil obteve-se resultado positivos para cada dia melhor a prática docente.

Em reuniões frequentes com os professores, o estudo contínuo o auxilia neste processo de estudo e troca de informações, por isso a formação continuada deve ser uma prática realizada por todos os profissionais da educação, pois os seres humanos e a sociedade são dinâmicos e mudam com frequência e a educação deve estar acompanhando essas mudanças. A prática dos professores consegue atingir as dúvidas apresentadas pelos professores iniciantes e vice-versa.

O trabalho desenvolvido mostra que o profissional da educação que possui uma formação consegue realizar um trabalho de alfabetização utilizando a oralidade como uma ferramenta indispensável em seu cotidiano escolar. Os discursos dos professores com relação a oralidade infantil demonstra que a criança como sujeito ativo pode ser atingido em todas suas dimensões se for bem estimulado em sua prática diária.

O espaço da sala é o local ideal para que as trocas de informações entre seus pares seja estabelecida, respeitando a faixa etária de cada turma de alunos, proporcionando um espaço estimulante, com inúmeros desafios, para que a criança desenvolva suas habilidades e potencialidades, socializando-se plenamente, mostrando assim que a escola é um espaço de construção de saberes.

Constatou-se ainda que os professores costumam estudar, planejar frequentemente suas aulas, tornando a aprendizagem dos alunos um processo mais prazeroso e assim contribuindo para estruturação do conhecimento das crianças, no qual a relação de aprendizagem da leitura e escrita tornam-se eficazes com o exercício da oralidade.

O letramento é um processo contínuo de estudo, favorece a ampliação do processo de alfabetização dos alunos por meio da prática dos professores e seus estudos contínuos. A verbalização dos alunos demonstra um enorme desenvolvimento da língua materna, onde o aluno traz de sua família certa forma de falar cotidiana que vai sendo moldada no espaço escolar com inúmeras atividades.

Evidencia-se nas falas dos professores que a formação inicial, nível universitário, ainda é escasso, principalmente sobre a prática pouco vivida pelos estudantes na área de educação. A relação entre a teoria e prática no estudo da formação em docência deve haver maior fortalecimento nos estudos, tornando a categoria do profissional mais alicerçada e sólida para o exercício da docência, podendo assim proporcionar uma melhor aquisição de conhecimentos que são necessários ao trabalho do professor.

As evidências apontadas no estudo acarreta à luz a grande importância do profissional querer estar sempre estudando, valorizando-se e consequentemente seu aluno será valorizado, criando um elo de boas aprendizagens, buscando estimular seu aluno em todas as aprendizagens alcançadas.

As evidências respondem aos questionamentos realizados na introdução da pesquisa, relatando a importância e os benefícios da oralidade para a aprendizagem cognitiva dos alunos desde a educação infantil. A Língua Portuguesa possui uma complexidade em sua gramática, com uma diversidade de gêneros textuais, mas tal riqueza requer do profissional um saber notório de conhecimentos para ser 
alcançada, aprofundada e assim desenvolver no aluno habilidades cognitivas para esta proficiência.

Muitos professores advindos de uma pedagogia tradicional buscam refletir em sua temática diária o que aprenderam, muitas vezes dificultando a aprendizagem dos alunos, a comunicação entre professor e aluno acaba se tornando fragmentada, necessitando quebrar paradigmas para uma evolução de sua teoria e prática embasada em conhecimentos relacionados a uma busca por conhecimentos juntamente com os alunos, uma parceria com um único objetivo, a aprendizagem.

A curiosidade das crianças deve ser aproveitada desde a Educação Infantil, pois como sendo um sujeito ativo requer do professor uma noção articulada com a atualidade, para assim tornar alfabetizador todo 0 ambiente e atividades que 0 professor possa intervir em sua oralidade desde muito cedo.

Em sua formação inicial, o professor precisa relacionar momentos teóricos e aplicálos em seus estágios, pois assim estão utilizando na prática, as teorias que aprenderam na sala de aula durante a graduação e adequando com a realidade dos alunos, buscando focar a infância de seus alunos, muitas vezes deixada de lado por inúmeras atribuições que são dadas as crianças, esquecendo que elas precisam brincar, movimentar-se, trazer o lúdico em suas relações e se comunicar com outras crianças, sendo ela sujeito de necessidades, podendo assim desenvolver todas as suas habilidades.

O desafio para estes profissionais é buscarem sempre formação continuada, um meio de compreender, refletir em sua didática, para que assim atue nos espaços de educação infantil, melhorando a cada dia. O professor em toda sua amplitude deve promover um aprendizado que leve a criança a ser um usuário de sua língua, promovendo um aprendizado com atividades lúdicas, tornando a aprendizagem prazerosa, trabalhando todos os eixos de atividades com os alunos.

\section{6.-Referências.}

Chaer, M.R., Guimarães, E. G.A. (2012). A importância da oralidade: educação infantil e séries iniciais do Ensino Fundamental. Pergaminho, (3): p. 71- 88.

Costa, G., Rossetti, F. (2003). Conversar para aprender a conversar. In: RossettiFerreira, M. C. et al. (Org). Os fazeres na Educação Infantil. São Paulo: Cortez, p. 81-83.

Elane, C., Oliveira, J.S., Rocha, M. L. (2007). Como as crianças adquirem e desenvolvem a linguagem. Disponível em: www.psicologia.pt/artigos/ver_artigo_licenciatura.php?codigo=TL0075.

Acesso em: 22 de out de $201 \overline{6}$.

Marconi, M. A., Lakatos, E.M. (2009). Fundamentos em metodologia científica. 6. ed. 7. Reimpr. São Paulo, Atlas.

Nunes, C. (2001). Aprendizagem ativa em crianças com Multideficiencia. Ministério da Educação, 1998-2001. 
Oliveira, M. M. (2007). Como fazer pesquisa qualitativa. Petrópolis: Vozes.

Oliveira, Z.M., Mello, A.M., Vitória, T., Ferreira, M.C. R. (2011). Creches: Crianças, Faz de Conta \&Cia. Petrópolis, RJ: Vozes, 2011.

Piaget, J (1990). A equilibração dasEstruturas Cognitivas-Problema Central do Desenvolvimento. Rio de Janeiro: Zahar Editores.

Vygotsky, S.L. (2003). A formação Social da Mente: o desenvolvimento dos processos psicológicos superiores. 7. ed. São Paulo: Martins Fontes.

Zorzl, J.L. (1993). Aquisição da Linguagem Infantil: desenvolvimento, alterações, terapia. São Paulo: Pancast. 